\title{
MICRO-ELECTROMECHANICAL SYSTEMS IN THE ECOLOGY
}

\author{
Stefan Kartunov \\ Technical University of Gabrovo, Department of Mechanical and Precision Engineering \\ 4 Hadji Dimitar St., 5300 Gabrovo, Bulgaria \\ Ph.: +(359) 66827365, fax: +(359)66801155, skartunov@abv.bg
}

\begin{abstract}
In the present paper a definition, a model for building of MEMS (micro-electromechanical systems), types, their advantages and disadvantages have been given. The elements and the components, from which they are built, the development and the prediction of market about them have been considered as well more important firms, that manufacture them. A classification of MEMS is made on the basis of their designation and the region, where they operate. A special place is separated on the application of MEMS in the ecology as well as concrete examples are indicated - developments of firms and own ones.
\end{abstract}

Key words: micro-electromechanical systems, ecology.

\section{Introduction}

Each element, device or system, replaced by a definite number of micro-components, can be defined as micro-system or MEMS [1]. A generally accepted model of micro-system is the model of standard controlling system (Fig.1), but not all micro-systems follow this scheme of controlling system. The micro-sensors in the system detect alterations in the parameter, which has to be controlled. The electronic controlling logics (system) processes the information from sensors, after that it makes a signal for operating the actuating micro-mechanisms (microactuators) supporting the controlled parameter within desired limits.

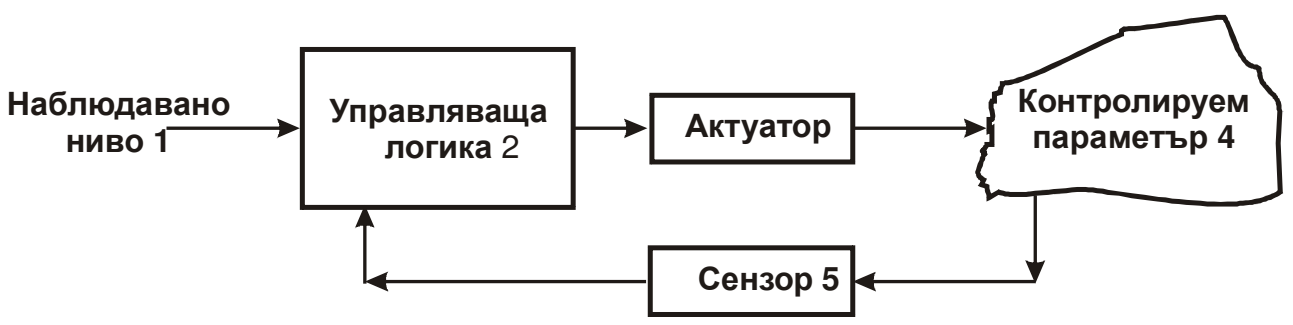

Fig. 1. Generally accepted model of micro-system

Legende: 1-Observed level; 2-Controlling logics; 3-Actuator; 4-Controllable parameter; 5-Sensor

Depending on the used physical phenomena, the micro-systems can be classified in principle as it is shown on the diagram in Fig.2 [2]. The different combinations from optical, electronic and mechanical phenomena form the types of systems in the micro-systematic technique optoelectronic, optomechanical MEMS and micro-optoelectromechanical systems (MOEMS). For systematizing the variety of micro-systems and their elements, the scheme shown in [3] can be used. A classification is imposed also according to the way of modeling nd the selected mathematical model for designing of micro-mechanical components, namely very often by means of the finite element method (FEM). According to this method, the model of the form of designed component is presented as one of the following basic types:

- elements from a type of beam - bar, beam, column;

- shell elements - slab, plate, shell;

- massive elements - elements with axially symmetric or arbitrary form.

The other kind of classification of micro-components as a base for selecting the technological process about their production is the type of material, from which they are produced and also the form of treated surfaces. 


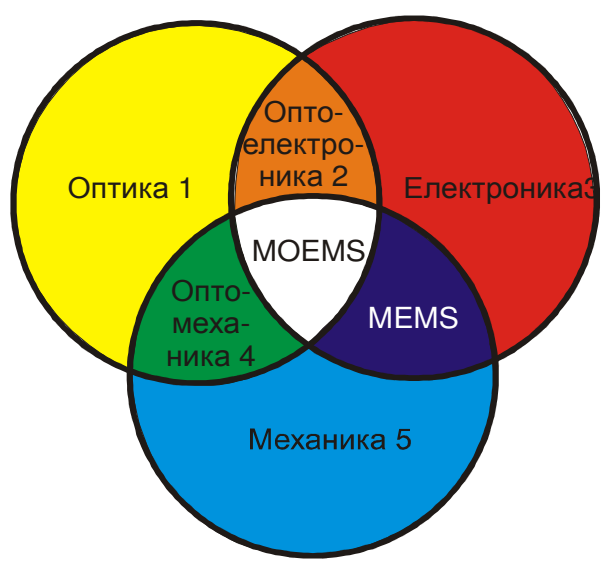

Legende: 1-Optics;

2-Optoelectronics;

3-Electronics; 4-Mechanics; 5-

Optomechanics

\section{Fig.2. Classification of micro-systems}

The development at the production of micro-systems is in the direction of a decrease of the expenses about materials and equipment, the quantity of technological operations as well improvement of their functional properties (accuracy, operating range, sensitivity, etc.) during a simultaneous increase of the reliability. By increasing of the complexity of micro-systems, the stage of automated design engineering will hold all time a more-important role in the process of production. Figure 3 visualizes the growth of MEMS in the industry in 2006 and the values, which are predicted to be reached in 2011.

\section{Markets for automotive MEMS sensors $2006-2011$ (CAGR=7\%)}

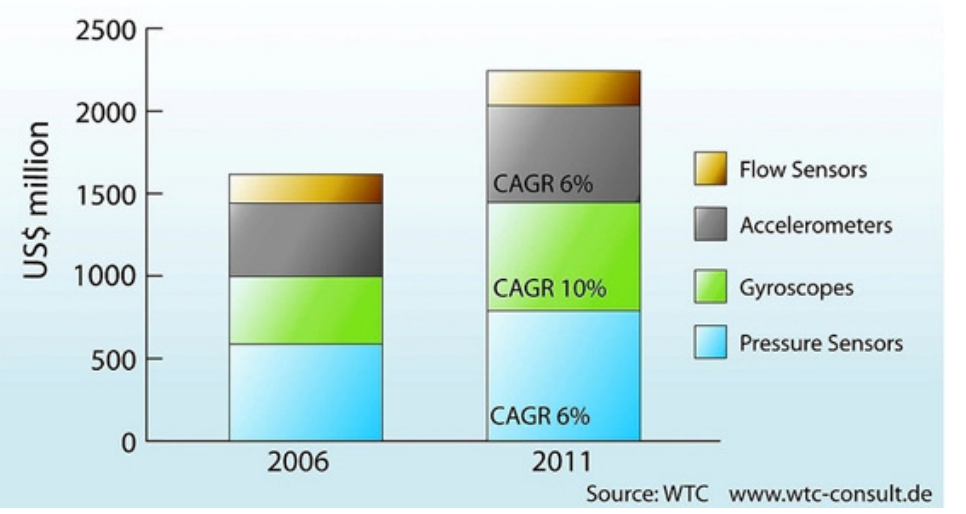

Fig.3. Growth of MEMS in the industry in 2006 and 2011

\subsection{Classification of MEMS in the ecology}

\section{Statement}

The classification of MEMS can be made on the basis of their designation and the field where they operate. According to fields of application MEMS about ecology are: of the water, the soil, the air, the atmosphere, the climate, etc. According to designation MEMS about monitoring and analysis in different branches of ecology are subdivided as follows:

- sensors for control of gases - detection of toxic and easily flammable, explosive gases as well for control of gas parameters as an expense, etc. Firms which work in this field are: Micro Chemical Systems, Alpha MOS, Neotronic Scientific Ltd, etc.

- satellite navigation and examination of the atmosphere and the Earth. The motion of water from the West to the East around the Equator taken down by Meteosat satellite is shown in Fig.4. 

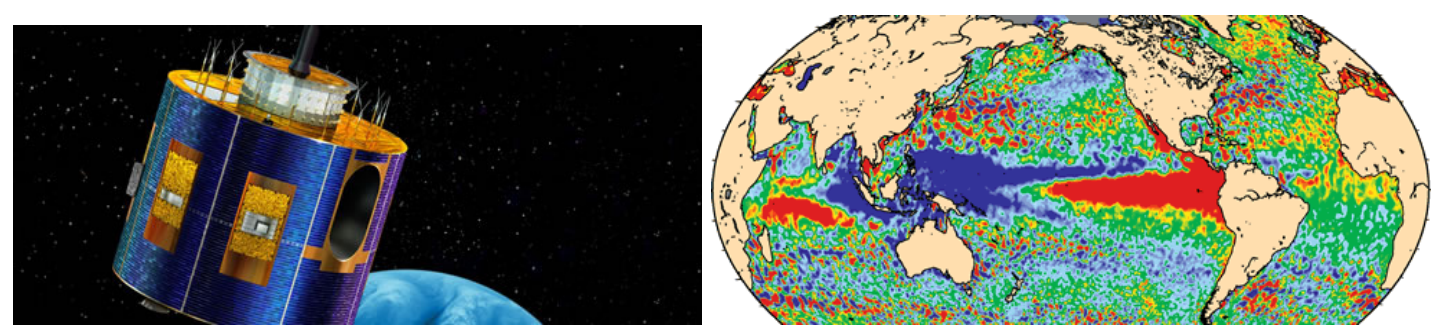

Fig.4. Photo of the Earth and the motion of water by Meteosat satellite

- sensors for humidity, acidity (pH-factor) of the soil, etc.;

- sensors for smell, electronic "noses" and detection of aromas;

- MEMS and sensors for change of the climate (Fig.5) and the comfort of living in the environment - rain, light, smoke, noise, etc.;

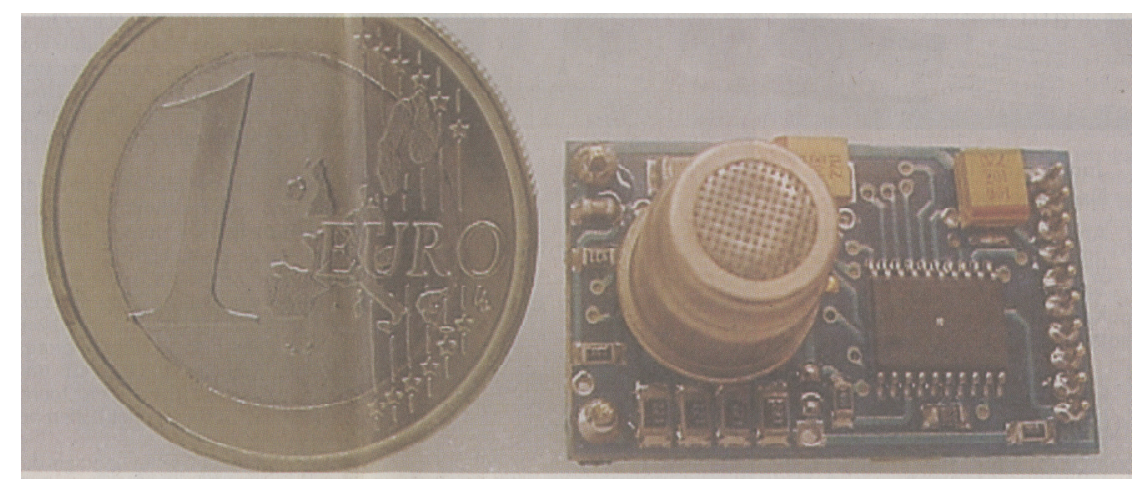

Fig.5. Sensor module for control of the climate according to the necessity

- sensors for industrial atmosphere and protection of the labour force and the articles from corrosion. The Multicomponential test of industrial gases is confirmed as a standard during tested IEC 60512-11-7(x), which is the nearest up to the application, especially at international norms. This is also referred to the next category of MEMS, at transboundary pollutions, interstate agreements, norms for pollutions in the telecommunications and the automobile technique, etc. In Fig.6 testers by HARTING firm are presented as for this purpose - testings of gases as nitrogen and sulphur oxides, hydrogen sulphide and chlorine.

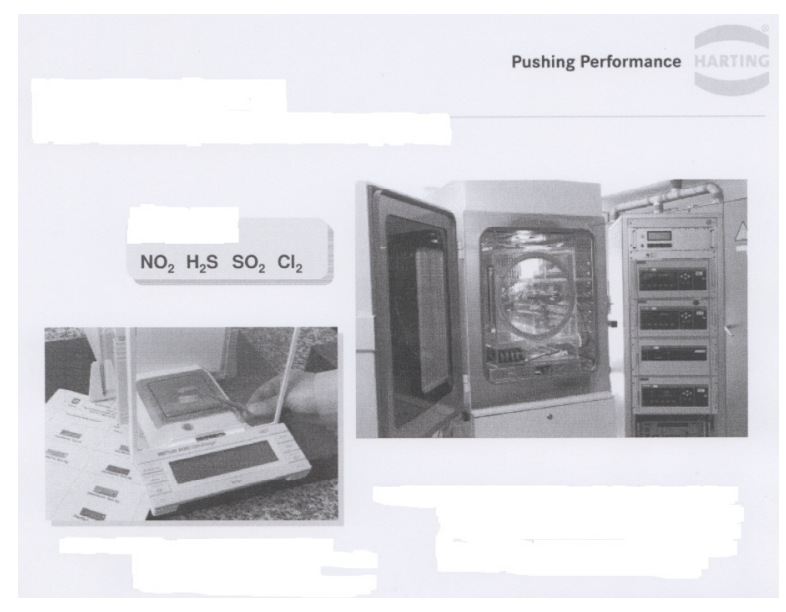

Fig.6. Devices with MEMS for testing of multicomponential industrial gases by HARTING firm (Germany) 


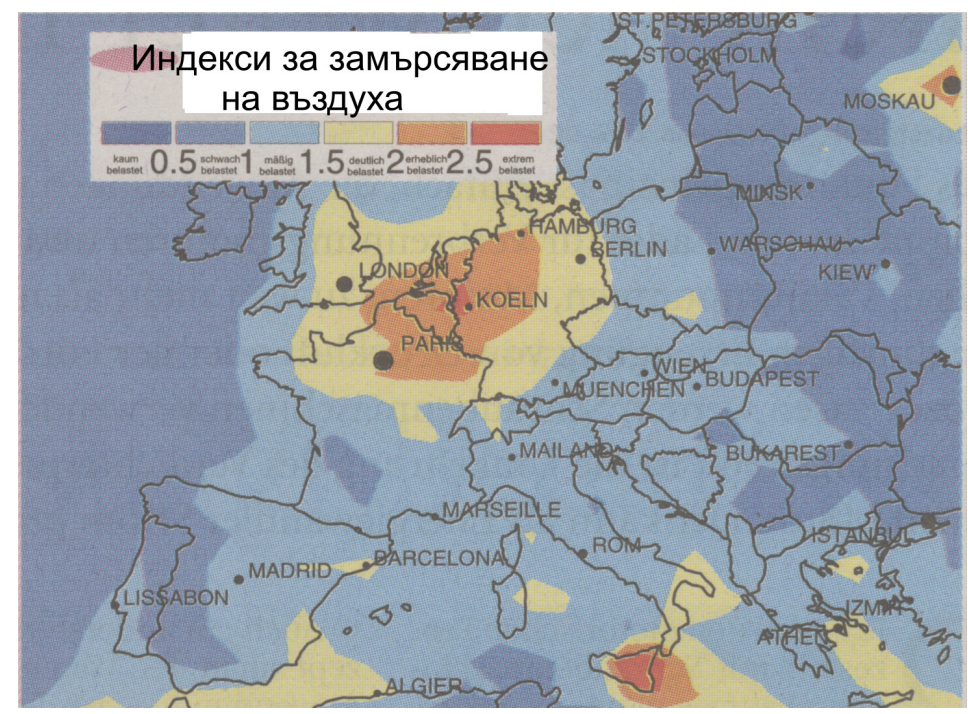

Fig.7. Map of Europe with indices for air quality-Indices for air pollution 0,5-2,5

- sensors for air purity - dust loading, purity, content of $\mathrm{CO}, \mathrm{CO}_{2}$, nitrogen oxides $\mathrm{NO}_{\mathrm{x}}$, sulphur oxides $\mathrm{SO}_{\mathrm{x}}$, heavy metals $\mathrm{Ca}, \mathrm{Ni}, \mathrm{Hg}$, aerosol $\mathrm{Pb}$, polycyclic aromatic hydrocarbons, arsenium Ar, hard particles (dust, ash), etc.;

- sensors for ozone and ozone layer;

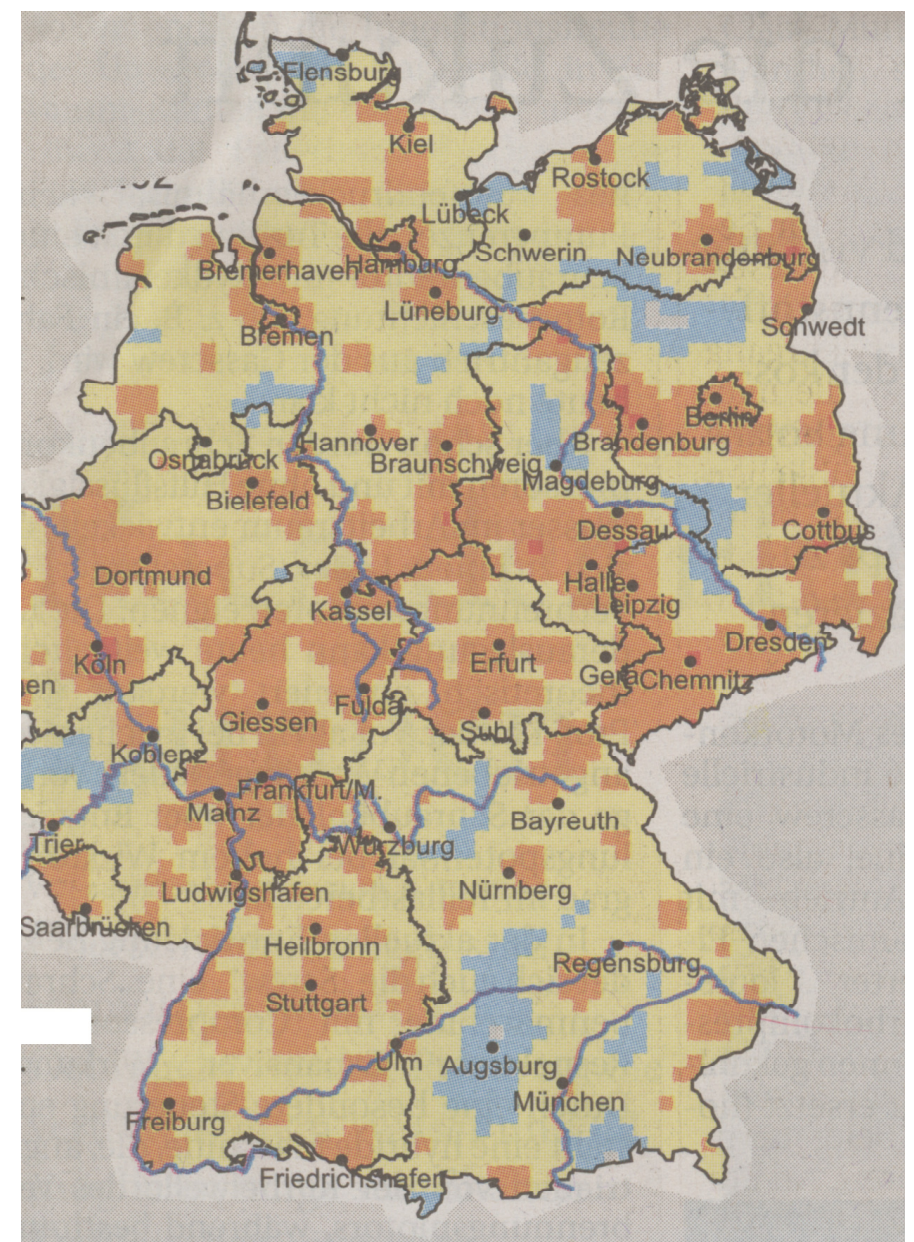

Fig.8. Map of Germany with maximum values of ozone taken down by MEMS

Note: Examplary values of ozone for the period in the beginning of September 2002 in a rising series are as follows: $1-40 \mu \mathrm{g} / \mathrm{m}^{3}, 41-100 \mu \mathrm{g} / \mathrm{m}^{3}, 101-160 \mu \mathrm{g} / \mathrm{m}^{3}$ and $>160 \mu \mathrm{g} / \mathrm{m}^{3}$ 
In the European Union (EU) the limit values, which are dangerous to the health from 50 $\mu \mathrm{g} / \mathrm{m}^{3}$, are not excluded. The norm for content of ozone in EU is $125 \mu \mathrm{g} / \mathrm{m}^{3}$. The values above $200 \mu \mathrm{g} / \mathrm{m}^{3}$ in the smog-situation lead to damages of health $[5,6]$.

- sensors for measurement of physical-mechanical magnitudes as compression, pressure, temperature, etc.

Strain Gauge (SG) sensors are widely distributed, since they are also used as a compound part of many other sensors for mechanical magnitudes. When a force $\mathrm{F}$ is applied on one solid body, its geometrical dimensions are changed - at compression the body is shortened (Compressive Strain) with Dl, but at tension it is elongated (Tensile Strain). Alterations of dimensions also occur at Torsion and Bending of the body. A group of sensors correspond to each of these four basic types of strains about their measurement. MEMS or SG-sensors for strains are with the largest application, which use the change of resistance of some materials at strains. For the first time this phenomenon was observed by Kelvin in 1856 about metal conductor, but its practical utilization began from $30^{\text {th }}$ years of the last century. Specific parameters of each SG-sensor are the resistance without mechanical force $\mathrm{R}$ which is some hundreds $\mathrm{W}$ and the Gauge Factor $\mathrm{GF}=(\mathrm{DR} / \mathrm{R}) / \mathrm{e}$, where $\mathrm{DR}$ is the change of resistance because of the strain.

Depending on the used material, two types of SG-sensors exist. The metal sensors for strains are composed of thin spiral folded conductor as they measure strains along its length that is called Sensor Axis. At sensors for strains with metal foil or foil from constantan, chromenickel, platinum or iron-nickel alloy is laid on plastic band which is sticked on the measured object with epoxy resin ordinarily. The counted metals are used because of their large resistance, the considerable admissible values of $\mathrm{Dl}$ and the large standing of fatigue precondition for long life of SG-sensors. The semiconductor sensors for strains possess an analogous structure, but they use the piezo-electric effect representing a change of the resistance of thin semiconductor layer at the strain.
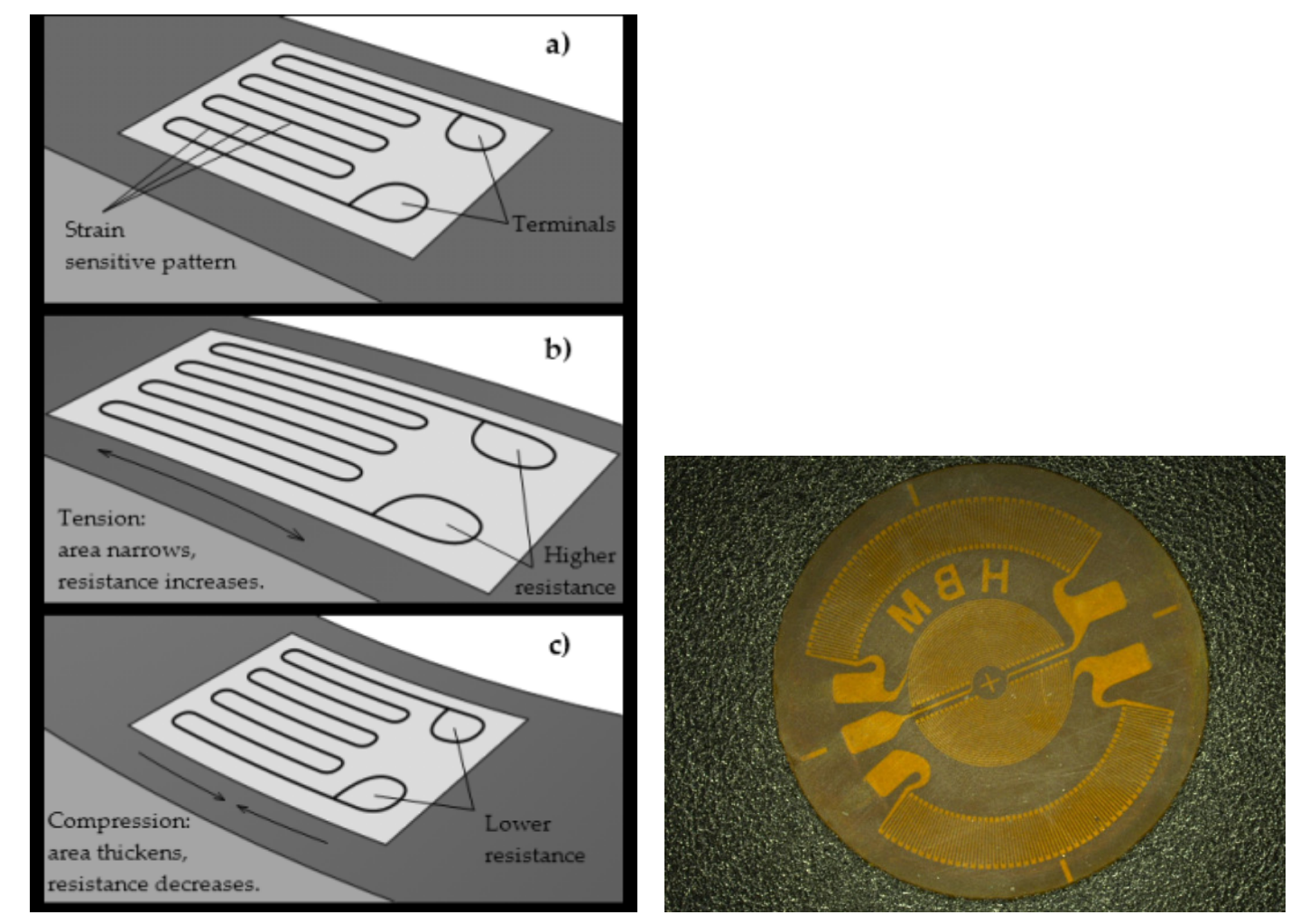

Fig.9. Strain Gauge sensors of HBM firm, USA 
The Pressure Sensors (PS) operate on the following principle:

The magnitude pressure $\mathrm{p}=\mathrm{F} / \mathrm{S}, \mathrm{Pa}$ expresses the force $\mathrm{F}$, which acts perpendicularly per a unit of area. Two ways for evaluation of the pressure exist. The measurement of absolute pressure denotes determination of its value towards the full vacuum (zero pressure). Sometimes this is marked by means of adding the letter "V" towards the denotation of PS and the letter "a" towards the unit of measurement (psia) or adding of "absolute" (for example mmHg absolute). The used denomination is Absolute Pressure Sensors. The relative pressure is the difference between absolute and atmospheric pressure, that is taken as a supporting level. In the last case the term Gauge Pressure is used, towards the denotation of sensor " $A$ " is added, but towards the unit of measurement - "g" (for example psig) or "gauge" (for example Pa gauge). The denomination is Gauge Pressure Sensors. A variety is Sealed Gauge Pressure Sensors, at which the comparison is made with exactly definite atmospheric pressure. It is usually at the moment of production of PS, that is "closed" in special sealed cavity. The measurement of difference between the two arbitrary pressures is used in a mass as well it is called Differential Pressure, at which the unit of measurement becomes psid. The denomination Differential Pressure Sensors is used. Given PS often possesses two or three operation modes for measurement of pressure. The output signal of PS is usually voltage that is several hundreds $\mathrm{mV}$, but at a necessity of its transmission to a distance it is amplified up to several $\mathrm{V}$ or it is transformed in current (very often 4-20 mA). Here, specific parameter is also the maximum super pressure which is between 1,5FS and 3FS. A basic element in the construction of almost all PS-sensors is the diaphragm. It represents a round thin flexible plate, which is bent proportionally to the difference in pressures from its two sides (Fig.10). Namely, such sensor was developed together with the Technical University of Darmschtadt, Germany and published in $[4,7]$.

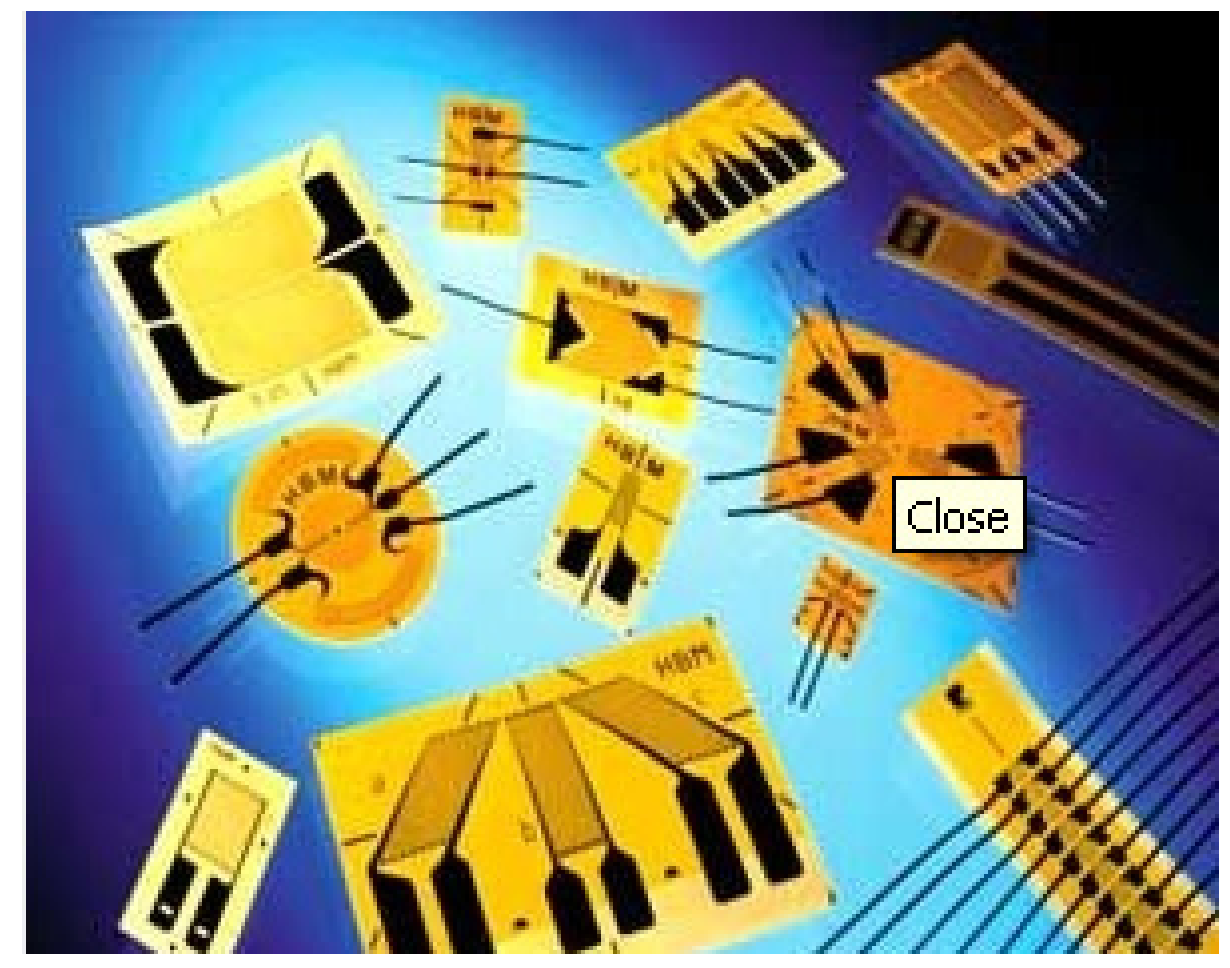

Fig.10. Pressure sensors

- sensors for "clean" premises;

- MEMS in the cleaning of surfaces, the restoration and the maintenance of works of art;

- sensors for the security, the reliability and the safety of work. 


\subsection{Study of MEMS with sensor for the ecology. Results}

The study includes designing, making and encapsulation of one piezoresistant pressure sensor on silicic shim which is destined to needs of the ecology. Figure 11 shows the cross-section of sensor, which has to be made. It has to consist of one thin membrane, on which the semiconductor resistances are located and they will transform the mechanical magnitudes in electrical ones. Because of the selected projection they are not seen, but they have to be located on the upper side of sensor. The sensor has to be dimensioned about maximum pressure from $1.10^{5} \mathrm{~Pa}$. The membrane has to possess an area from $2 \times 2 \mathrm{~mm}$.

At very large voltages in the membrane, linear errors arise in the transfer function of transducer. Because of this the maximum stress T, which appears in the membrane, has not be larger than $1 / 10$ from the failure stress. That is why, the thickness of membrane $h$ and the maximum deflection $\mathrm{x}$ have to be calculated. The formulae and constants, which are used, are as follows:

Mobility of the electrons in the silicon at room temperature: $\mu=1250 \mathrm{~cm}^{2} / \mathrm{Vs}$;

Charge of the electron: $\mathrm{e}=1,6.10^{-19}$.As;

Failure stress of the silicon: $\mathrm{T}_{\mathrm{B}} \approx 500 \mathrm{MPa}$;

Modulus of elastic deformation of the silicon: $\mathrm{E}=170 \mathrm{GPa}$;

Poisson's coefficient: $v \approx 0,26$;

Stresses in the rectangular membrane: $T=1,18 \cdot\left(\frac{b}{2 h}\right)^{2} \cdot p$

Mean deflection of the rectangular membrane: $x=\frac{b^{4}(1-v)^{2} \cdot p}{32 \cdot h^{3} \cdot E}$

Specific resistance for $\mathrm{n}$-doted silicon: $\rho=\rho=1 / e . n . \mu_{n}$

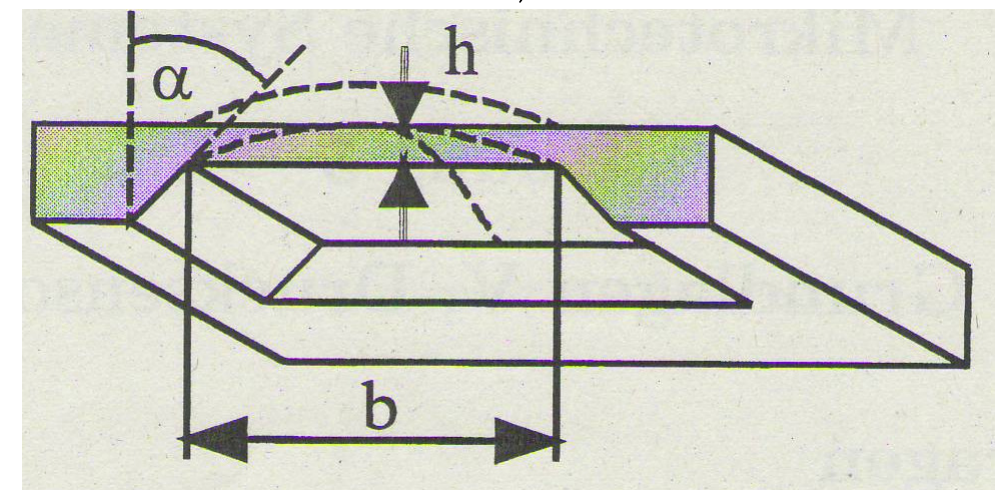

Fig.11. Section-view through the sensor from below

$$
\begin{gathered}
\mathrm{T}=\text { Тв } / 10 ; \text { Тв } \approx 500[\mathrm{MPa}] ; \mathrm{p}=10^{5}[\mathrm{~Pa}] ; \mathrm{b}=2[\mathrm{~mm}] ; \mathrm{h}=? \mathrm{x}=? \\
\mathrm{~T}=\text { Тв } / 10=500 / 10=50.10^{6}[\mathrm{~Pa}]
\end{gathered}
$$

The maximum stress and the deflection of membrane are:

$$
\begin{aligned}
& T=\frac{1,18 \cdot b^{2} \cdot p}{4 h^{2}} h=\frac{\sqrt{1,18 \cdot b^{2} \cdot p}}{4 T}=\frac{\sqrt{1,18 \cdot 2^{2} \cdot 10^{5}}}{4 \cdot 50 \cdot 10^{6}}=0,236[\mathrm{~mm}]=236[\mu \mathrm{m}] \\
& x=\frac{b^{4} \cdot(1-v)^{2} \cdot p}{32 h^{3} \cdot E}=\frac{2^{4} \cdot(1-0,26)^{2} \cdot 10^{5}}{32 \cdot 0,236^{3} \cdot 170 \cdot 10^{-9}}=12,25[\mu \mathrm{m}]
\end{aligned}
$$

It also follows to study: How are the planes of crystal orientated and with what kind of method of laying-on the surface layer can the membrane in shown form be made? The planes of crystal have to be indicated (Fig.12), how large is the angle $\alpha$ and how is the thickness of membrane adjusted exactly? 
$\alpha$

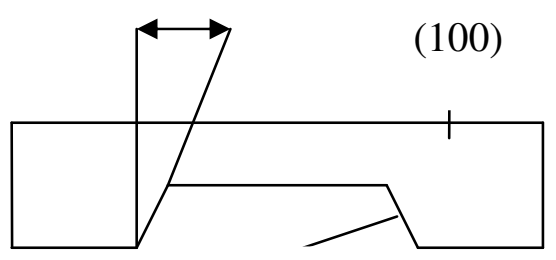

(111)

\section{Fig.12. Planes of crystal}

The membrane, which possesses the shown form in Fig.12, is received by means of anisotropic etching. The angle between directions (100) and (111) is equal to 54,74 ${ }^{\circ}$. The angle $\alpha$ is the difference from this angle to right angle.

$$
\alpha=90-54,74=35,26^{\circ}
$$

The thickness of membrane is inversely proportional to the time of etching $h=1 / t$, but the speed reaches to $3 \mu \mathrm{m} / \mathrm{h}$. The necessary thickness is achieved by means of the exact determination of the time of etching.

The resistances have to be realized in material doted with n-type of conduction. In the making of sensor, the density of electrons has to be adjusted on $n=10 \% / \mathrm{cm}^{3}$. The resistance without the action of piezo-electric effect from $1000 \Omega$ has to be accounted for along $200 \mu$ m length. It is necessary the resistances to be arranged in the form of a bridge circuit of switching-on for maximum sensitivity. Three possible arrangements exist, which are shown in Fig.13. The indicated formulae are with approximations and they can be used without assuming of a serious error.

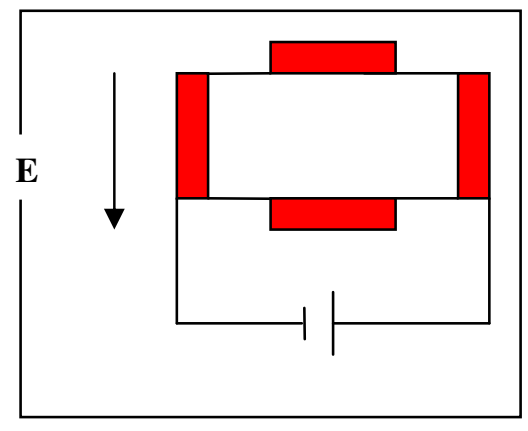

a)

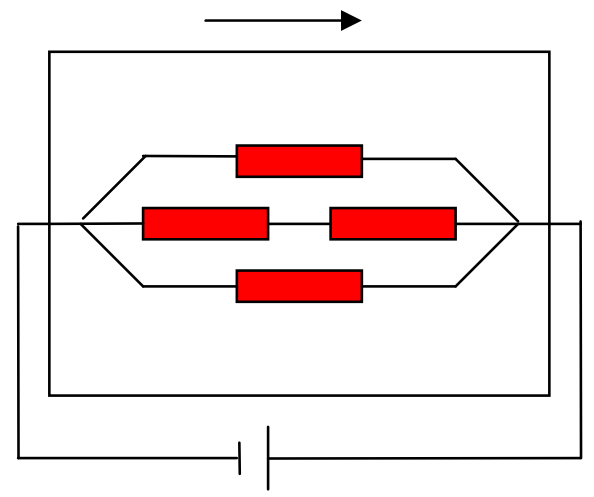

b)

Fig.13. Bridge ciruits of switching-on the resistances

Legende: a) mixed arrangement - small linear error, R1/R2 - resistance in longitudinal direction towards the current network, R3/R4 - resistance that is crosswise of the current network, $b$ ) longitudinal arrangement - large linear error, c) cross arrangement - small linear error, large voltage in the zero point (no gezeigt)

The data are as follows:

$$
\begin{aligned}
& \mathrm{E}=1,6.10^{-19}[\mathrm{As}] ; \mu \mathrm{n}=1250[\mathrm{~cm} 3 / \mathrm{Vs}] ; \mathrm{n}=10^{16}\left[\mathrm{~cm}^{3}\right] \\
& \mathrm{l}=200 \mu \mathrm{m}=0,2[\mathrm{~mm}] \\
& \mathrm{R}=1000[\Omega]
\end{aligned}
$$




$$
\begin{aligned}
& \rho=1 / e \cdot n \cdot \mu_{n}=1 / 1,6 \cdot 10^{-19} \cdot 10^{16} \cdot 1250 \approx 0,5 \\
& R=\frac{\rho \cdot l}{A} \Rightarrow A=\frac{\rho \cdot l}{R}=\frac{0,5 \cdot 200}{1000}=0,1\left[\mu \mathrm{m}^{2}\right]
\end{aligned}
$$

In order to study the production of pressure sensor with membrane and transducers, it is necessary to analyze the technological process of production as well as to describe the technological scheme of basing - how and with what technology the separate working operation have to be performed.

In Fig.14 piezoresistant pressure sensor with membrane from silicon, that is made by means of anisotropic etching on the opposite side of silicic shim, is presented. In the place of maximum deformation of the membrane, the strongest piezoresistant effect is appeared. For forming the active structure of sensor, stoppers are used which are made by means of diffusion or ion implantation. The silicic p-layer, alloyed with high content of boron (concentration of boron admixtures $5.10^{19} \mathrm{~cm}^{3}$ ), is etched very more slowly in potassium hydroxide $(\mathrm{KOH})$ than it is weakly alloyed. This possibility is applied during production of the membrane. However, in order to be able to create a notion about one similar product which is suggested in trade type by Novansensor firm - in Fig. 15 two photos can be seen that are proposed to use in the ecology and it is produced according to the variant from Fig.14.

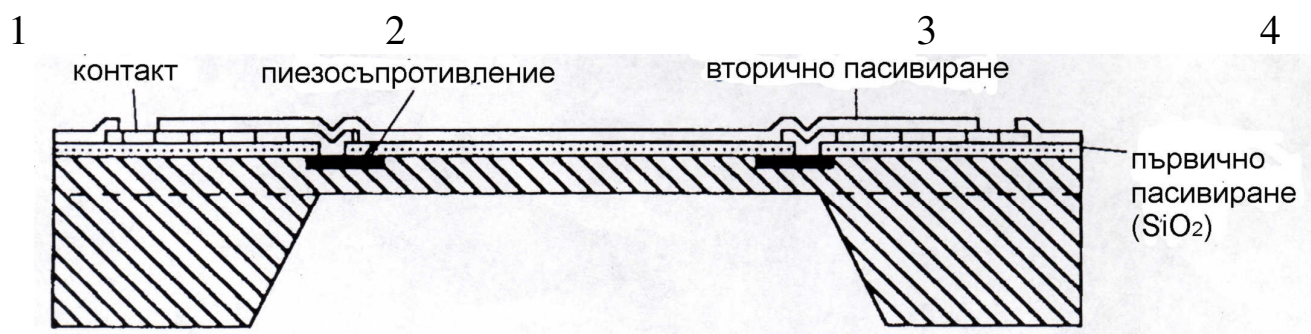

Fig.14. Piezoresistant silicic pressure sensor

Legende: 1-contact; 2-piezoresistance; 3-secondary passivation; 4-primary passivation $\left(\mathrm{SiO}_{2}\right)$
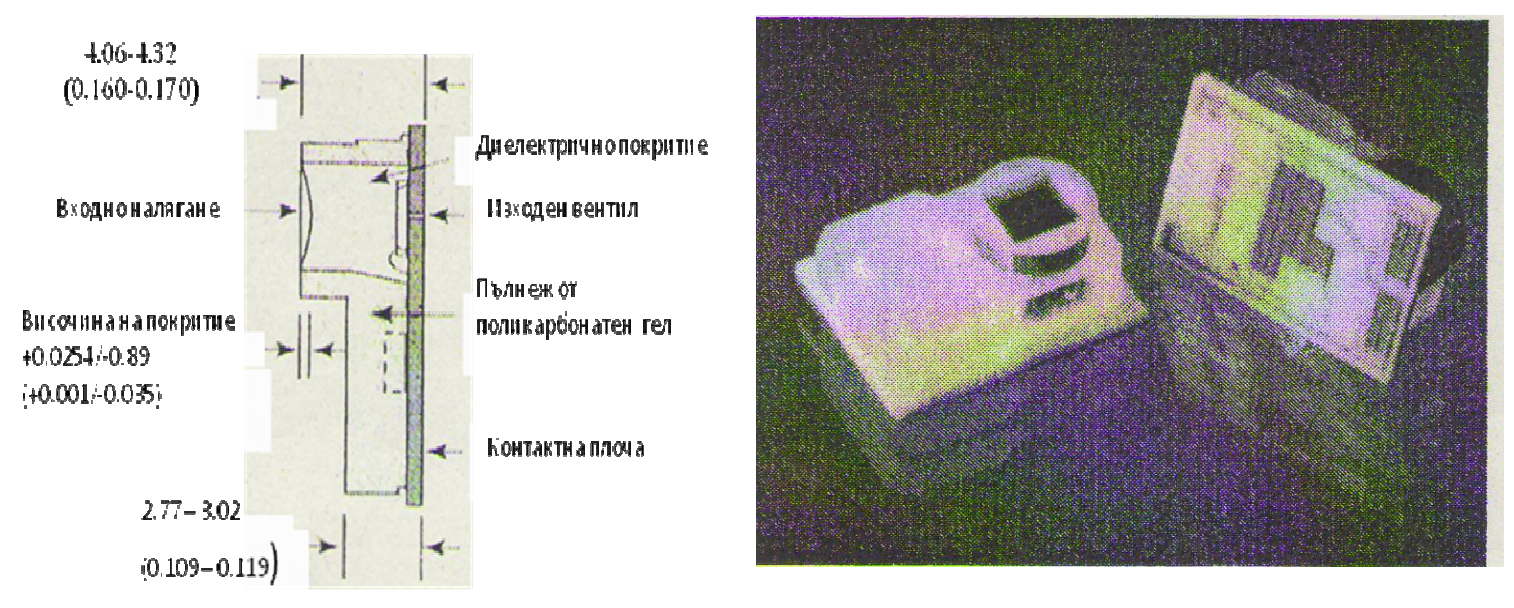

\section{Fig.15. Principal scheme and photo of pressure sensor by Novasensor firm with application in the ecology}

Legende: Dielectric coating; Output valve; Filling from polycarbonate gel; Contact plate; Input pressure; Height of coating 


\title{
2.3. Application
}

The present development of MEMS leads to a multilateral introduction of miniature systems for analysis in the ecology. In this field the microsystems are developed predominantly for analysis of water and gases. As an example sensor for cigarette smoke will be pointed, which can recognize selected and determinate types of smokes during combustion. The conditions of introduction, especially in industrial mediums as for example thermo-electric power stations of coal, require protection against dust (ash) and corrosion, external moisture and changes in the temperature, shocks and vibrations, electromagnetic fields as well gases disturbing its operation (for instance from solvents, welding works, natural smokings with materials). The research group with Prof. H. Baltes from the Physical Electronics Laboratory of ETN-Zurich has developed sensor microsystem representing a three-dimensional silicic chip for detection of harmful gases in the air. In it three types of sensor elements for measurement and analysis of three different physical magnitudes are integrated, at that with accuracy up to 1 milliardth part of the gramme. Masssensitive, capacity and calorimetric sensors are realized within the framework of common chip, together with the processing and controlling electronics. The introduced membranes with sensitive layers in many chemical sensors serve simultaneously as a protective layer between the measured medium and electronics. For example, the sensor developed by Siemens firm for residual emissions from hydrogen during control of the ignition of cylinders in the automobiles.

\begin{abstract}
Summary
A classification of MEMS is made on the basis of their designation and the region, where they operate. A special place is separated on the application of MEMS in the ecology as well as concrete examples are indicated - developments of firms and own ones.
\end{abstract}

\section{References}

1. Kartunov S., Todorova V., Microsystematic technique, University publishing house "V. Aprilov", Gabrovo, 2002 (in Bulgarian).

2. http://www.mems.colorado.edu

3. Kartunov, S., Integrated system for automated design engineering of functional elements from the microtechnique and selection of technological processes about their manufacture, Gabrovo, HT, 2007 (in Bulgarian).

4. Kartunov S., Develop, research and implement in the education process and in the industrial companies series of micro sensors for pressure and compression, Vrnjačka Banja, Serbia, RADMI - 2009, 16-19. September 2009.

5. Ненов Николай, Микропроцесорный сигнализатор радиоактивности, TARPTAUTINES MOKSLINES - PRAKTINES KONFERENCIJOS STRAIPSNIU RINKINYS, Kaunas, 2009 (in Russian).

6. Ненов Н., Интелигентна система за фонов мониторинг, Известия на ТУ - Габрово, 2010 (in Bulgarian).

7. Панайотов Т., Къртунов С., Разработка тонкого миниатюрного датчика давления, Красноярск (Русия), Современньіе проблемьі радиоелектроники, 2010, ISBN 978-5-7638-1940-3, P. $203-205$ (in Russian). 